\title{
To Describe Socio-Demographic Factors Related to Obesity in Rural Adult Population of Namkum Block in Ranchi District, Jharkhand, India
}

\author{
Anit Kujur ${ }^{1}$, Vidyasagar ${ }^{2}$, Vivek Kashyap ${ }^{3}$ \\ ${ }^{1}$ Junior Resident, ${ }^{2}$ Associate Professor, ${ }^{3}$ Professor \& Head, \\ Department of PSM, Rajendra Institute of Medical Sciences(RIMS), Ranchi, India - 834009
}

\begin{abstract}
:
Background: In the human history weight gain and fat storage has been viewed as signs of health and prosperity, but recent trend shows a shift in its prevalence from higher to lower socioeconomic level.

Aim and Objective: To Describe Socio-Demographic Factors Related To Obesity In Rural Adult Population Of Namkum Block In Ranchi District.

Material and Methods: Cross-sectional community based study was conducted at areas of Namkum Block of Ranchi District from September 2013 to December 2015. The adults who gave consent for the study were interviewed regarding the socio-demographic determinants (age, sex, education, marital status, occupation, income).

Statistical Analysis: Template generated in MS Excel Sheet and analysis was done on SPSS Software.

Result :Out of 500 Subjects prevalence of obesity was 21.9\%( males-53.6\%,females-46.4\%),between 41-50 years of age group (31.8\%), were Hindu( $47.2 \%$ ) belongs to upper class $36.4 \%$ followed by upper middle class was $27.8 \%$, middle class was $35 \%$.

Conclusion: Finally to conclude, obesity has no longer remained a problem of only upper socio economic class but Indian middle class has also dragged into the so called "problem of affluent.
\end{abstract}

Keywords: Obesity, Socio demographic factors.

\section{Introduction}

In the human history weight gain and fat storage has been viewed as signs of health and prosperity,but recent trend shows a shift in its prevalence from higher to lower socioeconomic level. Obesity can be seen as the first wave of a defined cluster of non communicable diseases called "New World Syndrome" creating an enormous socioeconomic and public health burden in poorer countries ${ }^{1}$. The World Health Organization has described obesity as one of today's most neglected public health problems, affecting every region of the globe $^{2}$. Today however standards of living continue to rise, weight gain and obesity are posing a great threat to the health of people worldwide ${ }^{3}$. Obesity is scientifically defined as condition of abnormal or excessive fat accumulation in adipose tissue ,to the extent that health may be impaired. It may be:-

* Hypertrophic obesity(enlargement of fat cell size)

* Hyperplastic obesity ( an increase in fat cell number)

* combination of both ${ }^{4}$.

Obesity is also expressed in terms of Body mass index (BMI).BMI is defined as weight in kilograms divided by square of height in meters $\left(\mathrm{kg} / \mathrm{m}^{2}\right)$.

Table showing Classification of BMI in Asian adult (additional cut-off points by WHO) $)^{5,6}$

\begin{tabular}{|l|c|c|}
\hline Category & BMI & Risk of co-morbidities \\
\hline Underweight & $\leq 18.5$ & Low (but increased risk of other clinical problems) \\
\hline Normal Weight & $18.5-22.9$ & Average \\
\hline Overweight & $23.0-24.9$ & Increased \\
\hline Obesity Class I & $25.0-29.9$ & Moderate \\
\hline Obesity Class II & $\geq 30$ & Severe \\
\hline
\end{tabular}

Source: Adapted from WHO 1995, WHO 2000 and WHO 2004.

Although BMI provides a convenient and simple measurement of obesity,a more important aspect of obesity is regional distribution of the body fat. People who tend to have low BMIs but high levels of abdominal fat are prone to NIDDM,hypertension and CHD. Obesity is a serious medical condition which need urgent attention throughout the world. 
WHO recently stated "the growth in the number of severly overweight adults is expected to be double of underweight during 1995-2025".India is the second most populous country in the world comprises $17 \%$ of the world population and contributes to $16 \%$ of the world deaths.Earlier developing countries like, India has focused scarce public health resources primarily on high prevalence of undernutrition.Currently these nations are facing double burden of undernutrition and overnutrition ${ }^{7}$. Obesity has reached epidemic proportion in India in the $21^{\text {st }}$ century, with morbid obesity affecting 5\% of the country population ${ }^{8}$. Between 1980 and 2008,the worldwide prevalence of obesity has become doubled. Today, half a billion people (12\% of the world's population) are considered obese."Obesity is a silent killer which causes $60 \%$ cases of Diabetes, $40 \%$ cases of Hypertension ,20\% cases of cardiovascular disease and stroke.As per WHO'S the world health statistics 2012 report,one in six adults are obese,one in ten are diabetic, and one in three has raised blood pressure?

\section{Obesity In India}

According to the National Family Health Survey (NFHS), the percentage of ever-married women aged 15-49 years who are overweight or obese increased from 11\% in NFHS- 2 to $15 \%$ in NFHS-3. Undernutrition is more prevalent in rural areas, whereas overweight and obesity are more than three times higher in urban areas. This may be due to lesser physical activity in the urban areas. Furthermore, undernutrition and overweight/obesity are both higher for women than $\operatorname{men}^{10}$. This dual disease pattern in women may have an endocrine basis, but more probably has its roots in societal and cultural mores, which prevent women from leading a healthy lifestyle. The prevalence of overweight and obesity is three times higher among women. The percentage of women who are overweight or obese is highest in Punjab (30\%), followed by Kerala (28\%) and Delhi $(26 \%)$, all of which are relatively richer states. The prevalence of underweight and overweight among men shows similar variations by age, education, and wealth index. The Jaipur Heart Watch (JHW) was a combination of multiple cross-sectional epidemiologic studies, performed in India in rural and urban locations. From these cohorts, subjects aged 20-59 years (men 4102, women 2872) were included. The prevalence of various risk factors: Smoking/tobacco use, overweight/obesity (BMI $\geq 25 \mathrm{~kg} / \mathrm{m}^{2}$ ) truncal obesity $(\mathrm{WHR} \geq 0.95$ men, $\geq 0.85$ women), hypertension, dyslipidemias, metabolic syndrome, and diabetes was determined.

Thus in Asian Indian subjects,escalating population-wide generalized obesity correlates strongly with increasing cardiovascular risk factors.Few studies has been done regarding prevalence of obesity which are as follow:-According to a study done by SK SADHUKAHN (2007) ${ }^{11}$ in Hooghly District the prevalence of obesity among adults was $1.3 \%$.

Another study done by N GOPINATH (1994) $\mathbf{1}^{2}$ and SUNITA ASTHANA (1999) ${ }^{13}$ observed prevalence of obesity was $27.8 \%$ in Delhi and $30.24 \%$ in Varanasi respectively.

The emergence of the obesity in India initially affected primarily the higher socioeconomic strata of the population living in urban areas but recent trends shows shift of prevalence from higher to lower socioeconomic level. Rising prevalence of obesity in india may be attributed to the various factors like sedentary life styles,unhealthyfood habits,cultural practice and increasing afluence of middle class people.Prevalance of obesity has increased in few years in rural areas also.In this context the present study is undertaken to describe socio demographic factors related to obesity among rural adults of Namkum block in Ranchi District.

\section{Materials And Methods}

Study Design: Cross-sectional community based study

Place of Study: The present study was conducted at areas of Namkum Block of Ranchi District.

Study period: September 2013 to December 2015.

Ethical Consideration: The study was conducted after approval by institutional Ethical Committee of the RIMS, Ranchi Interview with the subjects were conducted after their informed consent .

Consent: The participants were given adequate information verbally in local language about the nature, purpose and benefit of the study. Verbal and written informed consent was obtained from the participants.

Study Population: Adults aged 20 years and above.

Sample Size- 500.

Sampling technique: Cluster sampling method is used in the present study.

Stage 1: Total number of villages was obtained by Census 2011.

1. Listing of all villages of Namkum was done.

2. One village was considered as one Cluster.

3. Clusters (villages) were selected randomly by lottery method.

4. Number of clusters (villages) surveyed were fixed to 6 .

Mahilong was chosen as first sample cluster, second village derived to be Rampur. Similarly six (06) villages were selected for sampling randomly by lottery method. 
All the villages in group are listed and from these villages persons 20 years and above both male and female those willing to participate were interviewed.On entering chosen cluster, first lane was chosen randomly using lottery method. All the houses in the chosen lane were visited and data was collected from eligible study subjects. This was continued till the target from each cluster (06) was met.

Data Analysis: Data was collected, compiled and tabulated, and it was analyzed with the help of different statistical tests using SPSS software version 20.

Method of collection of data: With use of pre tested Questionnaire.

Study instruments: Physical instruments and questionnaire

\section{Physical instruments:}

i. Weighing Machine: Weight recorded with bathroom scale weighing machine.

ii. Stadiometer : To measure height.

iii. Measuring Tape: Non stretchable measuring tape used to measure waist circumference.

Questionnaire: It was a pretested semi- structured questionnaire to get the information from selected population in the study. The variables to be studied included socio demographic details ,measuring waist circumference and assessment of body mass index.

\section{Methodology}

House to house visit was carried out to identify the eligible adults. Rapport was established with the community with the help of medico-social work. 500 adults were surveyed and the rest were not included as they did not give consent for the study or they were unavailable at the time of study. Participants were declared unavailable if they were not available even after two house visits. The purpose of the study was explained and the verbal and written consent was obtained from the participants before starting the interview. The adults who gave consent for the study were interviewed regarding the socio-demographic determinants (age, sex, education, marital status, occupation, income). Height, weight and waist circumference were measured using stadiometer, weighing machine and non-stretchable measuring tape respectively. All the instruments used for the study were calibrated daily. The data was recorded in the prescribed Performa. Filling of the Performa, height, weight and waist circumference measurement was done at their own residence. Filling the Performa, examination of study participants and the required measurements were done. Repeated visits were made to ensure full coverage.

IV. Results

Table-1: Distribution of study subjects according to BMI (WHO Asia-pacific guidelines)

\begin{tabular}{|l|l|l|l|}
\hline BMI & Male & Female & Total \\
\hline$<18.5$ & $8(25.8 \%)$ & $23(74.2 \%)$ & $31(6.2 \%)$ \\
\hline $18.5-22.9$ & $82(30.5 \%)$ & $186(69.5 \%)$ & $268(53.7 \%)$ \\
\hline $23-24.99$ & $41(45 \%)$ & $50(55 \%)$ & $91(18.2 \%)$ \\
\hline$>25$ & $59(53.6 \%)$ & $51(46.4 \%)$ & $110(21.9 \%)$ \\
\hline Total & $190(38 \%)$ & $310(62 \%)$ & $500(100 \%)$ \\
\hline
\end{tabular}

Figures in parenthesis indicate percentage

In the present study, out of the total 500 study subjects, 268(53.7\%) were having BMI between 18.5$22.9,110(21.9 \%)$ were having BMI > 25,91(18.2\%) were having BMI between23-24.99 and 31(6.2\%) were having BMI of $<18.5$.

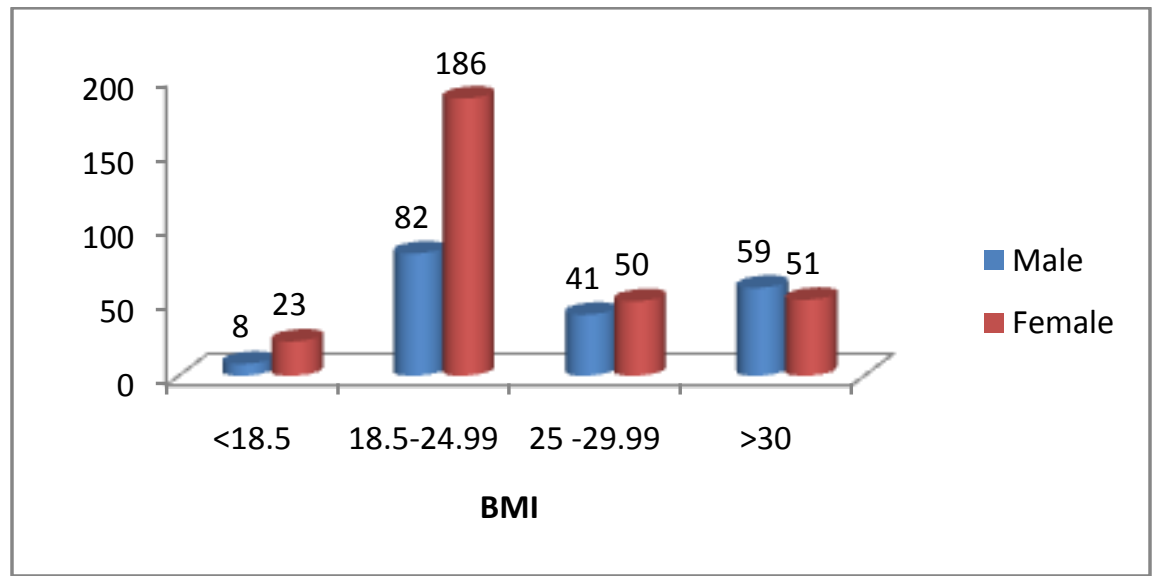

Fig 1: Bar diagram showing distribution of study subjects according to BMI. 
To Describe Socio-Demographic Factors Related To Obesity In Rural Adult Populati...

Table 2: Prevalence of obesity across the gender

\begin{tabular}{|l|l|l|l|}
\hline BMI & Male & Female & Total \\
\hline Obese $>25$ & $59(53.6 \%)$ & $51(46.4 \%)$ & $110(21.9 \%)$ \\
\hline Non-Obese(BMI <24.99) & $131(33.6 \%)$ & $259(66.4 \%)$ & $390(78.1 \%)$ \\
\hline Total & $190(38 \%)$ & $310(62 \%)$ & $500(100 \%)$ \\
\hline
\end{tabular}

Figures in parenthesis indicate percentage

In the present study, out of the total 500 study subjects, 59(53.6\%) were obese out of 190 males and $51(46.4 \%)$ were Obese out of 310 females.

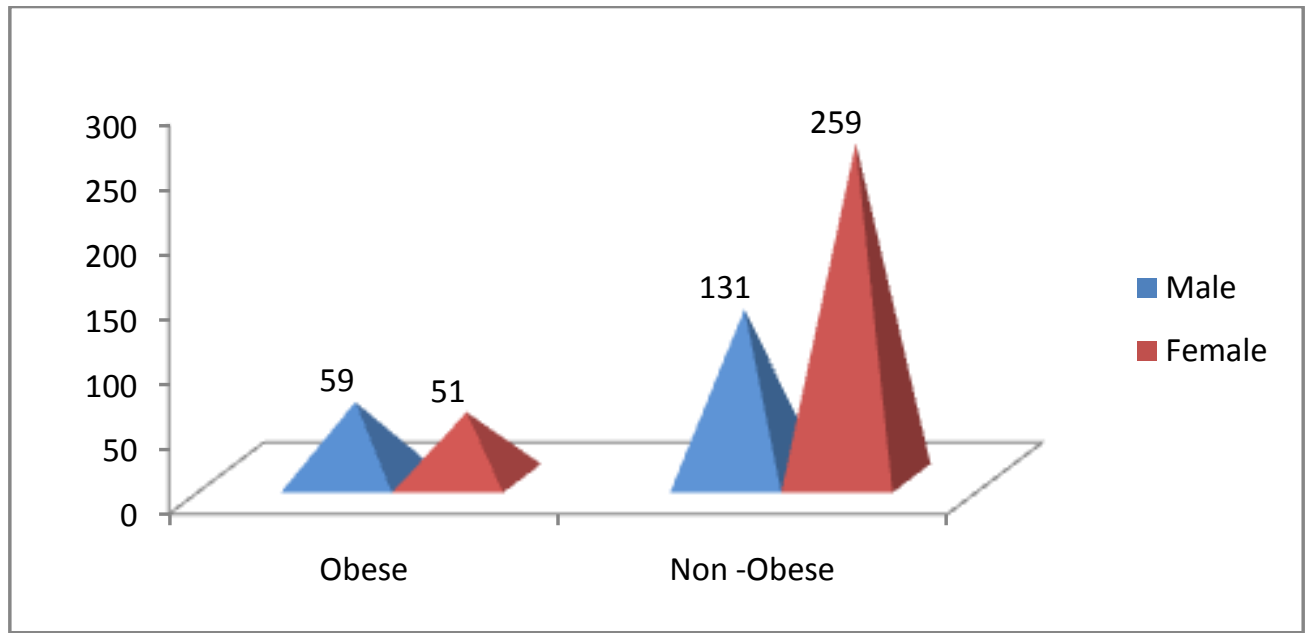

Fig 2: Bar diagram showing distribution of study subjects according to Obesity.

Table 3: Prevalence of obesity across age group.

\begin{tabular}{|c|c|c|c|c|c|}
\hline \multicolumn{3}{|c|}{ Age (in yrs) } & Obese & Non -obese & Total \\
\hline & \multirow{2}{*}{$\begin{array}{l}20- \\
30 \\
\end{array}$} & Count & 30 & 127 & 157 \\
\hline & & $\%$ & $27.3 \%$ & $32.6 \%$ & $31.4 \%$ \\
\hline & \multirow{2}{*}{$\begin{array}{l}31- \\
40\end{array}$} & Count & 8 & 80 & 88 \\
\hline & & $\%$ & $7.3 \%$ & $20.5 \%$ & $17.6 \%$ \\
\hline & \multirow{2}{*}{$\begin{array}{l}41- \\
50 \\
\end{array}$} & Count & 35 & 31 & 66 \\
\hline & & $\%$ & $31.8 \%$ & $7.9 \%$ & $13.2 \%$ \\
\hline & \multirow{2}{*}{$\begin{array}{l}51- \\
60 \\
\end{array}$} & Count & 11 & 35 & 46 \\
\hline & & $\%$ & $10.0 \%$ & $9.0 \%$ & $9.2 \%$ \\
\hline & \multirow{2}{*}{$\begin{array}{l}61- \\
70 \\
\end{array}$} & Count & 10 & 91 & 101 \\
\hline & & $\%$ & $9.1 \%$ & $23.3 \%$ & $20.2 \%$ \\
\hline & \multirow{2}{*}{$\begin{array}{l}71- \\
80 \\
\end{array}$} & Count & 11 & 8 & 19 \\
\hline & & $\%$ & $10.0 \%$ & $2.1 \%$ & $3.8 \%$ \\
\hline & \multirow{2}{*}{$\begin{array}{l}81- \\
90\end{array}$} & Count & 5 & 18 & 23 \\
\hline & & $\%$ & $4.5 \%$ & $4.6 \%$ & $4.6 \%$ \\
\hline \multirow{2}{*}{\multicolumn{2}{|c|}{ Total }} & Count & 110 & 390 & 500 \\
\hline & & $\%$ & $100.0 \%$ & $100.0 \%$ & $100.0 \%$ \\
\hline \multicolumn{3}{|c|}{ Chi square $=69.326$} & & & \\
\hline
\end{tabular}

Observation in the study shows that prevalence of obesity was higher among 41-50 years age group (31.8\%) followed by 20-30 years age group (27.5\%), 51-60 \& 71-80 years age group (10\%) and 61-70 years age group $(9.1 \%)$ and $61-70$ years age group ( $7.3 \%)$.Difference in the prevalence of obesity among different age groups was found to be statistically significant $\left(X^{2}=69.326, P\right.$ value $\left.=.000\right)$.

Table 4: Prevalence of obesity across the Socioeconomic status.

\begin{tabular}{|l|l|l|l|}
\hline Socio-economic class & Obese & Non-Obese & Total \\
\hline Upper class & $4(3.6 \%)$ & $7(1.7 \%)$ & $11(2.2 \%)$ \\
\hline Upper Middle class & $30(27.2 \%)$ & $78(20 \%)$ & $108(21.6 \%)$ \\
\hline Middle class & $35(31.8 \%)$ & $65(16.6 \%)$ & $100(20.1 \%)$ \\
\hline Lower Middle Class & $31(28.2 \%)$ & $176(45.1 \%)$ & $207(41.4 \%)$ \\
\hline Lower class & $9(9.2 \%)$ & $65(16.6 \%)$ & $74(14.7 \%)$ \\
\hline Total & $110(21.9 \%)$ & $390(78.1 \%)$ & $500(100 \%)$ \\
\hline & Chi square $=23.540$ & P value $=.000$ & \\
\hline
\end{tabular}


Observation in the study shows that out of 500 subjects, prevalence of obesity among upper class was $36.4 \%$, upper middle class was $27.8 \%$, middle class was $35 \%$, lower middle class was $15 \%$ and lower class was $12.2 \%$. Difference in the prevalence of obesity across the socioeconomic status was found to be statistically significant $\left(X^{2}=23.540, P\right.$ value $\left.=.000\right)$.

Table 5: Prevalence of obesity across the religion

\begin{tabular}{|l|l|l|l|}
\hline Religion & Obese & Non Obese & Total \\
\hline Hindu & $52(47.1 \%)$ & $202(51.8 \%)$ & $254(50.8 \%)$ \\
\hline Sarna* & $46(41.8 \%)$ & $171(43.8 \%)$ & $217(43.4 \%)$ \\
\hline Muslim & $1(1.1 \%)$ & $2(0.6 \%)$ & $3(0.6 \%)$ \\
\hline Christian & $11(10 \%)$ & $15(3.8 \%)$ & $26(5.2 \%)$ \\
\hline Total & $110(21.9 \%)$ & $390(78.1 \%)$ & $500(100 \%)$ \\
\hline Chi square = 375.257 & P value $=.000$ \\
\hline
\end{tabular}

Table 5 shows, prevalence of obesity was higher among Hindu (47.2\%) followed by in Sarna (41.8\%) and in Christian $(10 \%)$ and was found to be statistically significant $\left(X^{2}=375.257, \mathrm{P}\right.$ value $\left.=.000\right)$.

\section{Discussion}

The present cross sectional study was carried in areas of Namkum Block of Ranchi district among 500 adults aged 20years and above to describe the Socio demographic factors related to obesity .

Table 1: shows ,out of total 500 study subjects ,268(53.7\%) were having BMI between 18.5-22.9, $110(21.9 \%)$ were having BMI >25,19( 18.2\%) were having BMI between 23-24.9 and $31(6.2 \%)$ were undernourished having BMI less than 18.5.

Table 2: shows, out of 500 study subjects surveyed, According to the Asia Pacific BMI guidelines ,overall prevalence of obesity was $21.9 \%$ ( males-53.6\%,females-46.4\%), prevalence of pre obese/overweight was $18.2 \%$ (males-45\%,females-55\%), 53.7\% were in the normal range (males-30.5\%, females-69.5\%) and $6.2 \%$ were under nourished(males- $25.8 \%$, females-74.2\%). Prevalence of overweight was higher among females compared to males, but prevalence of obesity was higher among males compared to females.

High prevalence of obesity in males may be due to life style related factors like increased consumption of alcohol and smoking with high intake of food rich in fat (i.e non vegetarian food). But a number of physiological processes are believed to contribute to an increased storage of fat in females.

In a study conducted by Rao CR and Kamat $\mathrm{V}$ et al ${ }^{15}$ reported that, prevalence of obesity (BMI> 30) was $6.6 \%$,over weight (BMI > 25) was $21.4 \%$ according to WHO BMI classification.

In a study conducted by Deshmukh $\mathrm{P} \mathrm{R}$ et $\mathrm{al}^{16}$, overall prevalence of obesity (According to WHO Asia -Pacific guidelines ,BMI > 25) was 5.13\%, out of which $5.1 \%$ in males,5.2 \% in females, prevalence overweight(BMI > 23) was $6.5 \%$, out of which $6.5 \%$ in males and $5.4 \%$ in females.

In a study conducted by $\mathrm{N}$ Gopinath et al prevalence rate was more in females compared to males. $\mathrm{N}$ Gopinath et al in their study observed that, the prevalence rate of obesity was more in females $(33.4 \%)$ compared to males $(21.3 \%)^{12}$

In a study conducted by Haldiya $\mathrm{K} \mathrm{R}$ et $\mathrm{al}^{16}$, overall prevalence of obesity (Asia pacific classification, BMI > 25)was reported to be $26.2 \%$ (males $11.7 \%$,females $14.5 \%$ ).

Table 3 shows, prevalence of obesity was higher among 41-50 years age group (31.8\%) followed by 20-30 years age group (27.5\%), 51-60 \& 71-80 years age group (10\%) and 61-70 years age group (9.1\%) and $61-70$ years age group ( $7.3 \%$ ). Difference in the prevalence of obesity among different age groups was found to be statistically significant.

Similar observations were made by $\mathrm{N}$ Gopinath et al. ${ }^{12}$ and Sunitha Asthana et $^{13}$ al found a direct relationship between age and prevalence of obesity. Prevalence of obesity showed an increasing trend over the successive age period. Prevalence of obesity increased from $8 \%$ in 15-20years age group to 50\% in women aged 50 years and above. The prevalence was highest in the age group 40 years and above.

$\mathrm{N}$ Gopinathet al ${ }^{12}(1994)$ observed the increasing trend in the prevalence of obesity in females with increase in age from $22.8 \%$ in 25-34 years to $43.1 \%$ in 55-64 years and overall prevalence was $27.8 \%$.

As per NFHS-2(1998-1999), the prevalence of obesity in females increased with increasing age. Lowest prevalence rate of 0.45 was found in the age group of 20-24years and highest prevalence of $3.9 \%$ was found in the age group of 35-49years and the overall prevalence was $5.8 \%$. With increase in age, physiologically there is decrease in the metabolic rate and increase in the sedentary lifestyle contributing to increase in obesity. 
Table 4 shows, out of 500 subjects, prevalence of obesity among upper class was $36.4 \%$, upper middle class was $27.8 \%$, middle class was $35 \%$, lower middle class was $15 \%$ and lower class was $12.2 \%$. Difference in the prevalence of obesity across the socioeconomic status was found to be statistically significant.

Table 5 shows, prevalence of obesity was higher among Hindu(47.2\%) followed by in Sarna $(41.8 \%)$ and in Christian (10\%).

Similar findings In a study conducted by Rao C R et al ${ }^{15}$ among People having sedentary and light physical activity had BMI $\geq 30 \mathrm{~kg} / \mathrm{m}^{2}$ among Christians and Hindus 4 (10.8\%) and 34 (6.3\%) individuals had BMI $\geq 30$ $\mathrm{kg} / \mathrm{m}^{2}$ respectively

\section{Conclusion}

Finally to conclude, obesity has no longer remained a problem of only upper socio economic class but Indian middle class has also dragged into the so called "problem of affluent.

\section{References}

[1]. Pednekar MS.Association of body mass index with all cause and cause-specific mortality : Findings from a Prospective cohort study in Mumbai,India.Int J Epidemiol 2008;37:524-535.

[2]. World Health Organization. Preventing chronic diseases: A vital investment. World Global Report. Geneva: 2005.

[3]. David W,Haslam,W Philip T James.Obesity.lancet 2005; 366 : 1197-1209.

[4]. Park K.Park's Textbook of Preventive and Social Medicine.19 th ed .Jabalpur,India: M/s Bananridas Bhanot publishers 2007: p. 332-335.

[5]. Obesity: preventing and managing the global epidemic. Technical Report SeriesNumber 894. Geneva; WHO: 2000

[6]. World Health Organisation. The Asia Pacific Perspective: Redefining obesity and its treatment.. Geneva, Switzerland: World Health Organisation; 2000.

[7]. The Global challenge of the obesity and The International Obesity Task force(International Union of nutritional Sciences)available from www.iunsweb.org/the- global -challenge- of- Obesity- and- the- International- Obesity- task- force(assessed on 13.07.12).

[8]. Garrow JS.Obesity and related Diseases.London:Churchill Livingstone; 1988. P. 1-16.

[9]. http://health.India.com/news/world-health-statistics-2012-one-in-six-adults-obese-one-in-three-hypertensive-in-tendiabetic(assessed on 19.08.12)

[10]. http://www.nfhsindia.org/nfhs3.html.(Assessed on 6 march,2012) .

[11]. Sadhukhan SK,Bose K,Bharda M.Age variations in overweight men \& women in rural areas of Hooghly district,West Bengal.Indian Journal of Public Health 2007 ; 51 (1) : 59-61.

[12]. Gopinath N, Chanda SL,Jain p,Shekhawat S,Tandon R.An epidemiological study of obesity in adults in the urban population in Delhi. J Assoc Physicians India 1994 ; 42 (3) : 212-215.

[13]. Sunitha Asthana,Gupta VM.Role of biological factors in development of obesity.The Ind J Nutr Dietet $1999 ; 36: 263-267$.

[14]. Deshmukh PR, Gupta SS, Dongre MS, Bharambe C ,Maliye C, Kaur S et al. Relationship of anthropometric indicators with blood pressure levels in rural Wardha. Indian J Med Res 2006:657-64.

[15]. Rao CR, Kamath VG, Shetty A, Kamath A. A cross-sectional analysis of obesity among a rural population in coastal Southern Karnataka, India. AMJ 2011, 4, 1, 53-57.

[16]. Haldiya K R ,Murli L,Mathur and Sachadev R. Lifestyle related risk factors for cardiovascular disease in a desert population of India 